\title{
How Carbon Pricing Impacts the Selection and Optimization of a Gas Turbine Combined Heat and Power System: An Australian Perspective
}

\author{
Chanel A. Gibson, Mehdi Aghaei Meybodi, and Masud Behnia
}

\begin{abstract}
Businesses are currently being forced to re-evaluate their energy practices with the emergence of carbon pricing in many developed nations including Australia's relatively new carbon pricing mechanism. This paper expands on a previous investigation by these authors. A gas turbine CHP system is examined to determine the financial impact Australia' $s$ carbon price has on the installation incentive to help businesses become more energy efficient. Three economic cases were considered to ensure a comprehensive analysis was conducted. The system was unprofitable under all configurations indicating a gas turbine based system was not financially beneficial when applied to this case study. However, the system became slightly more economical when the carbon price was introduced indicating the installation of a CHP system may be beneficial under carbon pricing.
\end{abstract}

Index Terms-Australia's carbon price, combined heat and power system, gas turbine partial load, thermo-economic optimization.

\section{INTRODUCTION}

As businesses come to terms with operating in a carbon-constrained economy, they look to methods that enable their business practices to become more energy efficient in order to reduce their carbon footprint. Australia has recently joined the climate change fight by introducing a carbon pricing policy, which came into effect in July 2012. The Australian scheme has a significant amount of international linking potential with similar schemes promoting a carbon-constrained world rather than just an individual economy.

One method of reducing carbon emissions is the installation of a cogeneration system, or as it is more commonly referred to a combined heat and power (CHP) system. A CHP system produces more than one output from a single input, which in turn greatly increases energy efficiency. In this case electricity and heat are produced.

This work aims to build on the previous work conducted by [1] which considered a steam turbine based CHP system operating under Australia's carbon price. This investigation utilizes the same case study and economic data however a gas turbine is used as the prime mover of the system. A gas turbine offers a competitive alternative to a steam turbine. According to [2] a gas turbine, compared to a steam turbine, has more uses for the thermal output without requiring extensive

Manuscript received September 24, 2013; revised January 13, 2014.

The authors are with The University of Sydney, NSW, Australia (e-mail: m.behnia@sydney.edu.au). additional capital equipment, lower noise emissions and a much shorter start-up time (10 minutes to one hour for a gas turbine compared to one hour to one day for a steam turbine). This last advantage is of particular interest to business where longer start-up times (especially for systems only operating at set times during the day) translate to additional expenditure. Like [1], this investigation takes place using information regarding the carbon price in Australia after its introduction, providing more concrete results as to its impact compared to the work conducted by [3] which relied on the speculative impacts of Australia's carbon price.

\section{AUSTRALIA's CARBON PRICE}

Australia's carbon pricing policy came into effect on 1 July 2012 and consists of two pricing phases. The first pricing phase is scheduled to operate for a period of three years until 30 June 2015. At this stage, the policy operates as a carbon tax whereby carbon emissions are charged by the tonne at a fixed price of $\$ 23 / \mathrm{tCO}_{2}$-e increasing each financial year to $\$ 24.15$ and $\$ 25.40$ in 2013-14 and 2014-15 respectively [4]. There is no cap placed on the number of units available for purchase throughout this stage.

The carbon pricing policy will transition to a market driven system on 1 July 2015. Here, the open market is responsible for determining the price of a carbon unit. This stage resembles a traditional emissions trading scheme (ETS). As the scheme moves into the new phase, during a transitional period of three years, a price ceiling will be in effect to ensure the market remains free from any sharp fluctuations in the carbon unit price [5]. The price ceiling is expected to be set at a value $\$ 20$ above the price of an European Union Emissions Trading System (EU ETS) allowance [5]. This pricing phase also includes provisions for a substantial amount of international linking further expanding the carbon market. Reference [1] provides an estimate of the carbon price for the lifetime of the system. The starting price and the price of a carbon unit at the conclusion of the system's lifetime as estimated by [1] are included in Fig. 1.

As this paper aims to identify the direct impact of the carbon price, several economic scenarios have been established to enable these results much like the scenarios in [1]. These cases are summarized in Fig. 2. Case one was business as usual. That is, in this case it was assumed no carbon pricing policy had been introduced in Australia and therefore the system was not financially liable for its carbon emissions. Regardless of the policy future in Australia, this case will always be valid. The second case, case two, has a 
carbon pricing policy introduced into the economy. However, since there are many factors and limitations that determine a system's liability under the policy, this system was not financially liable and therefore had to pay no penalty for the release of carbon emissions. The final economic scenario considered, case three, required the system to operate in an economy with carbon pricing like case two, however it was assumed this system was financially liable to pay the penalty for the release of carbon dioxide emissions.
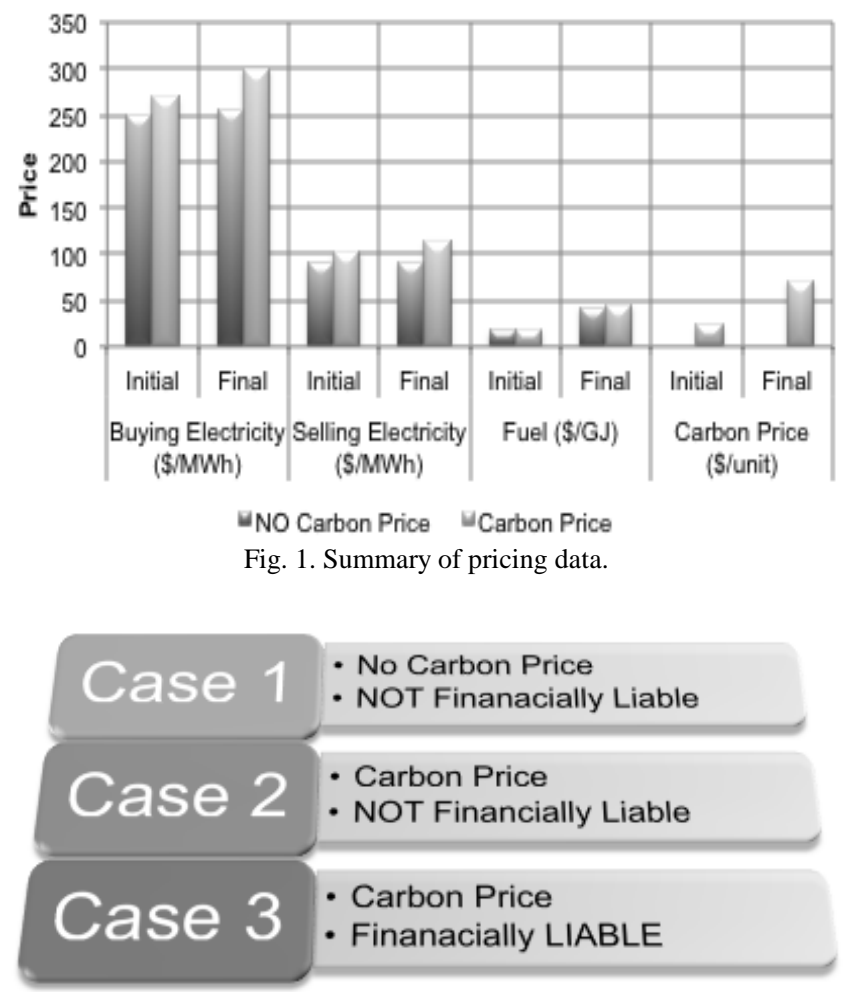

Fig. 2. Summary of economic cases.

Consequently, case three required the quantity of carbon equivalent emissions to be computed, as this would determine the liability of the system. Since direct monitoring of the site was not possible in this context, a method specified in [6] and described in [7] was used. The proposed method relies on the known quantity of fuel consumed in order to calculate the emissions.

\section{A. Economic Modeling}

Extensive economic modeling regarding the impact of Australia's carbon price on the price of purchasing electricity, the price paid as the feed-in tariff, and the price of purchasing fuel (natural gas) was carried out in [1]. For completeness of this paper a summary of these prices are presented here in Fig. 1. The initial price is indicative of the price at the system's commissioning and the final price at the conclusion of the system's 20 year lifetime.

\section{CASE STUDY}

In order to be able to accurately compare the results obtained from this investigation with the results presented in [1], the same case study was applied with several modifications in order to accommodate the new prime mover.

The case study used in [1] depicted the electricity and heat demand profile for a large scale winery located in New South Wales, Australia. In [1], high pressure steam was exhausted from the steam turbine and separated with $10 \%$ routed to steam cleaning (utility heat demand) and the remaining passed through a condenser to generate hot water (process heat demand). This required a separation on the demand profile into the two heat demand categories. In the new system the exhaust generated by the gas turbine was fed through a heat recovery boiler that produced the necessary heat. Therefore, the heat demand was combined into a single demand in Fig. 3 to represent the thermal needs of the plant.

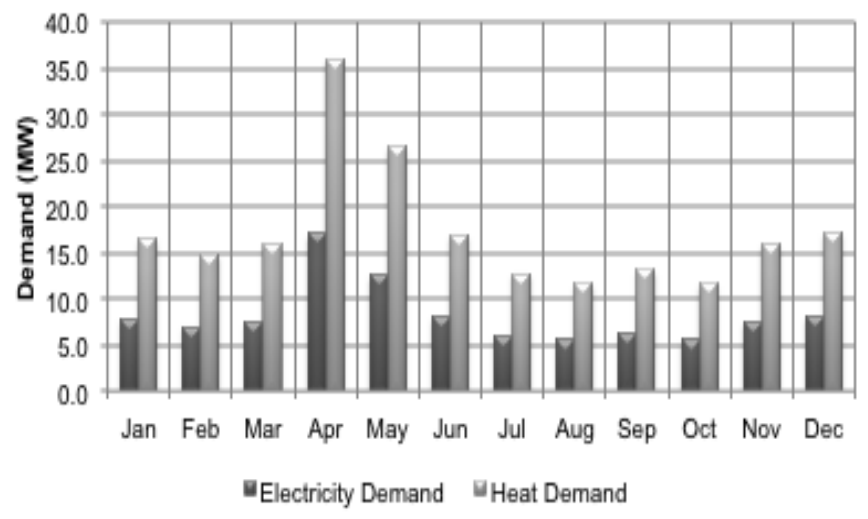

Fig. 3. Demand profile for case study.

The demand profile is reproduced here in Fig. 3 based on the information published in [1]. The key observation to note from this demand profile is the heat demand is far greater than the electricity demand in all months of the year. There is a spike in electricity and heat demand in April that coincides with peak season in the winemaking process.

\section{SYSTEM DESIGN}

Fig. 4 shows the simple gas turbine based CHP system that has been adopted for this investigation. The gas turbine, fuelled by natural gas fed to the combustor, drives a generator responsible for producing electricity. A heat recovery boiler (HRB) was added to process the thermal output exhausted by the turbine and turn it into usable heat. If the recovered heat was insufficient to satisfy the demand, a back-up boiler was included in the system. The back-up boiler was also fuelled by natural gas.

A grid connection was established with the system to allow the purchase of any shortfall electricity required by the system from the grid. In addition, a second connection to the grid also allowed the system to feed back to the grid any excess electricity produced for the payment of a feed-in tariff.

The system was required to work at off design conditions in order to ensure the most economical operating strategy was identified. To this end, equations modeling the partial load performance of the gas turbine, namely the fuel mass flow rate, were obtained from [3] and used in the thermodynamic analysis of the system. Several additional thermodynamic parameters were required in order to complete the model. These included the efficiencies of the generator, HRB, and back-up boiler. These were assigned values of $98 \%$ [8], 75\% [3], and $80 \%$ [2] respectively. 


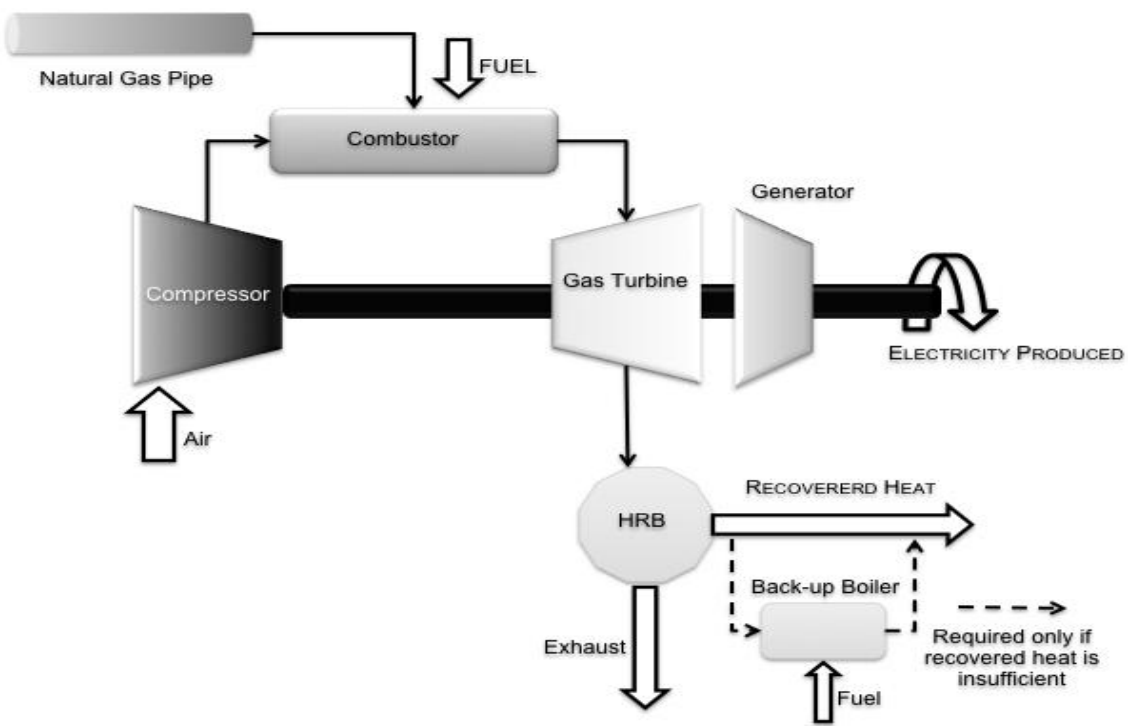

Fig. 4. Gas turbine CHP system design.

\section{ECONOMIC ANALYSIS}

\section{A. Economic Indicators}

The thermodynamics of the system were combined with the costs associated with the implementation and the running of the system to produce the first economic indicator that determined the overall profitability of the system, net present worth (NPW). NPW was calculated by computing the difference between the present worth of benefits and the present worth of costs. This is the same equation used by [1] and is reproduced here in (1).

$$
\begin{aligned}
N P W & =\sum_{j=1}^{k}\left\{S V_{j}\left(\frac{1}{(1+i)^{L T}}\right)-C C_{j}\right\} \\
& -\sum_{y=1}^{L T}\left(\frac{1}{(1+i)^{y}}\right)\left\{C P+\sum_{m=1}^{N}\left[\sum_{j=1}^{k}\left(O M_{j}+C o F_{j}\right)\right.\right. \\
& +P_{b} \times C_{e l, b}-P_{C H P, r} \times C_{e l, b}-\dot{H}_{C H P, r} \times C_{h} \\
& \left.\left.-P_{C H P, s} \times C_{e l, s}\right]_{m} \times \tau_{m}\right\}_{y}
\end{aligned}
$$

where $k$ is the total number of equipment, $j$ is the equipment number, $S V$ is the salvage value (\$), $i$ is the interest rate, $L T$ is the lifetime (years), $C C$ is the capital cost $(\$), y$ is the year, $C P$ is the carbon price (\$), $N$ is the number of time intervals in the demand profile, $m$ is the month, $O M$ is the operation and maintenance costs $(\$), C o F$ is the cost of fuel $(\$), P_{b}$ is the amount of electricity purchased $(\mathrm{kW}), C_{e l, b}$ is the cost to purchase electricity $(\$ / \mathrm{kWh}), P_{C H P, r}$ is the electricity produced by the CHP system $(\mathrm{kW}), \dot{H}$ is the quantity of recovered heat $(\mathrm{kW}), C_{h}$ is the cost of the recovered heat $(\$ / \mathrm{kWh}), P_{C H P, s}$ is the excess electricity produced by the system, $C_{e l, s}$ is the feed-in tariff $(\$ / \mathrm{kWh})$ and $\tau$ is the time interval.

The system possessing the greatest amount of economic potential was characterized by the maximum $N P W$ achievable. A negative $N P W$ was indicative of a system that was unprofitable.

The second economic indicator that was used is the payback period (PBP). That is, the period of time required for the initial expenditure to be recovered. The equation used by [1] to compute the PBP of the system, $n$, is given here in (2).

$$
\sum_{y=1}^{n} N A P_{n}\left(\frac{1}{(1+i)^{y}}\right)+\sum_{j=1}^{k} S V_{j}\left(\frac{1}{(1+i)^{n}}\right)=\sum_{j=1}^{k} C C_{j}
$$

where $n$ is the payback period (years) and NAP is the net annual profit (\$).

\section{B. Additional Economic Parameters}

Several additional properties were required in order to complete the analysis. In regards to the system lifetime, the interest rate, and the salvage value; these values were all taken from [1] and assigned values of 20 years, 6\%, and $10 \%$ respectively.

Equation (1) required the capital and operation and maintenance (O\&M) costs of the system to be known. Capital costs for the gas turbine, generator, HRB, and back-up boiler were extracted from published literature in [3]. Similarly, the O\&M cost for the system was also available in [3] with a single cost covering the gas turbine, generator, and HRB. An estimation of the O\&M costs of the back-up boiler was also published in [3].

\section{METHOD}

$M A T L A B$ was used as a platform to write an optimization code to determine the nominal capacity of the system with the most economic potential and hence the operating strategy for that system. The following methodology was used when writing the code. For each of the perspective nominal capacities specified:

1) The properties of the system at the specified nominal capacity were calculated.

2) The electricity and heat demand required for the respective month was obtained from Fig. 3.

3) The partial load of the system was varied between 20 and $100 \%$ with $0.1 \%$ increments.

4) With the partial load specified, the partial load conditions were calculated to provide the electricity generated and recovered heat at this level of operation. 
5) The net annual profit (NAP) was calculated and multiplied by the respective economic factor.

6) The previous step was repeated for the 20 year lifetime of the system, producing 20 values which were subsequently summed and stored.

7) The process was repeated for each partial load specified.

8) The most economical value obtained was extracted along with its partial load. This partial load became the operating strategy for that month.

9) A total of 12 values, one for each month in the demand profile, were obtained and summed and placed in (1).

10) The capital costs of the system were subtracted from the salvage value at the conclusion of the system lifetime. This value was also substituted into (1) allowing NPW to be calculated. This value along with the nominal capacity was stored.

11) The above process was repeated for each of the nominal capacities specified.

12) The maximum $N P W$ achieved represented the most economical system.

\section{RESULTS AND DISCUSSION}

The resulting optimum nominal capacities obtained along with their respective $N P W$ values are summarized in Fig. 5. Unlike the results in [1] which reported cases one and two as profitable systems and case three as unprofitable, all three cases in this investigation resulted in an unprofitable system evidenced by the negative $N P W$ values recorded in Fig. 5 . However, the order depicting the profitability of the systems remained unchanged between the two investigations with case two identified as the most profitable system producing an $N P W$ value of $\$-1.61 \times 10^{7}$ followed by case one resulting in an $N P W$ of $\$-1.9 \times 10^{7}$ and finally case three with $\$-2.6 \times 10^{7}$. This indicates that the introduction of the carbon price in Australia has the ability to promote on-site power generation in the form of a CHP system. Due to the extreme unprofitability of each of the economic cases, there was no PBP identified, that is, the capital costs of the systems would never be recovered.

The most profitable of the three systems also produced the largest nominal capacity at 14.2 MW followed by case one with 13.9 MW and case three with a nominal capacity of 13.27 MW. Since the benefit of producing electricity on-site rather than purchasing from the grid is much greater in case two due to the increase in the price of electricity compared to natural gas, a larger system was generated. At nearly $1 \mathrm{MW}$ smaller in size compared to case two, case three had the additional financial burden of being liable for the carbon price. This placed significant strain on the profitability of the system and as a result decreased the system size.

Fig 6, Fig. 7, and Fig. 8 demonstrate the operating strategies for cases one, two and three respectively. In case one, the system produced electricity to follow the demand in all but the peak month of April. This trend is easily identifiable in Fig. 6. Producing electricity at these levels does not produce the required heat in the demand profile forcing the system to rely on the back-up boiler in every month of the year. Similar results are recorded for the operating strategy for case two upon inspection of Fig. 7. This type of operating strategy indicates it was more financially beneficial for the system to purchase fuel to produce electricity rather than purchasing electricity from the grid. It also meant it was advantageous for the system to purchase natural gas to fuel a back-up boiler in order to meet the heat demand rather than purchasing fuel to operate at a higher partial load or purchasing a larger gas turbine and feeding the excess electricity produced as a result of the increased heat recovery to the grid.

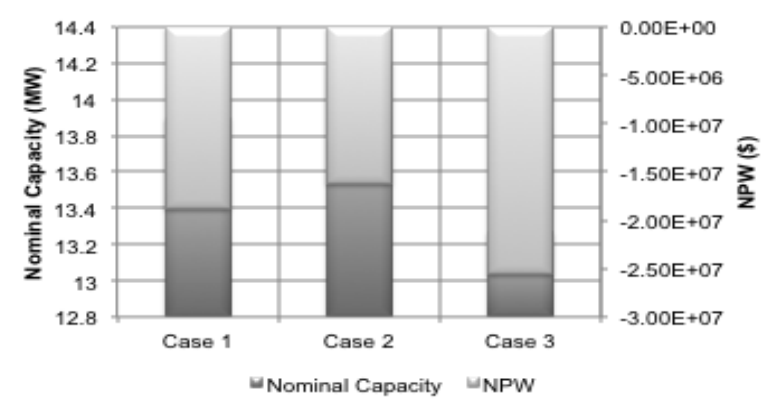

Fig. 5. Results of nominal capacity and NPW.

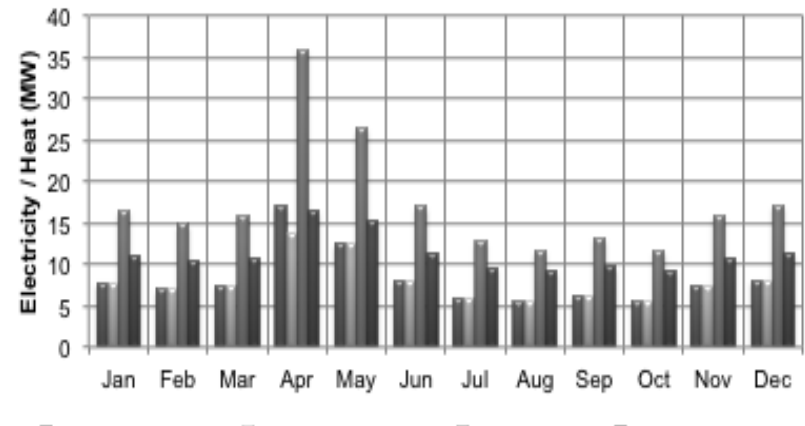

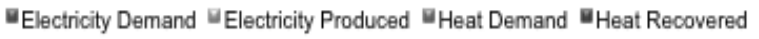

Fig. 6. Operating strategy for case one.

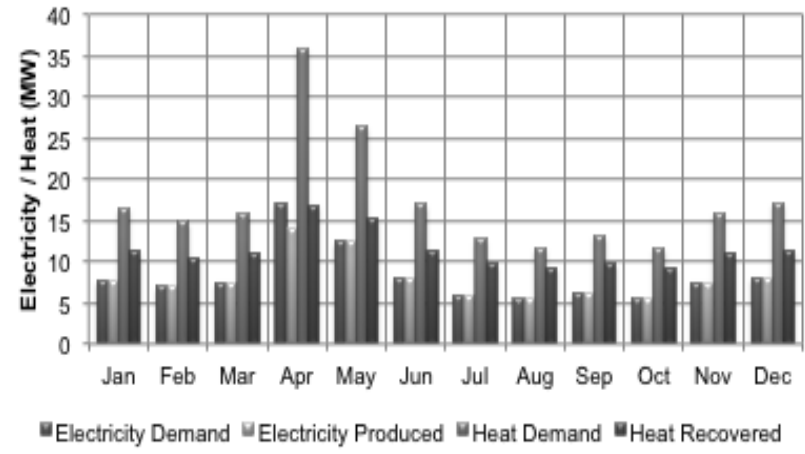

Fig. 7. Operating strategy for case two.

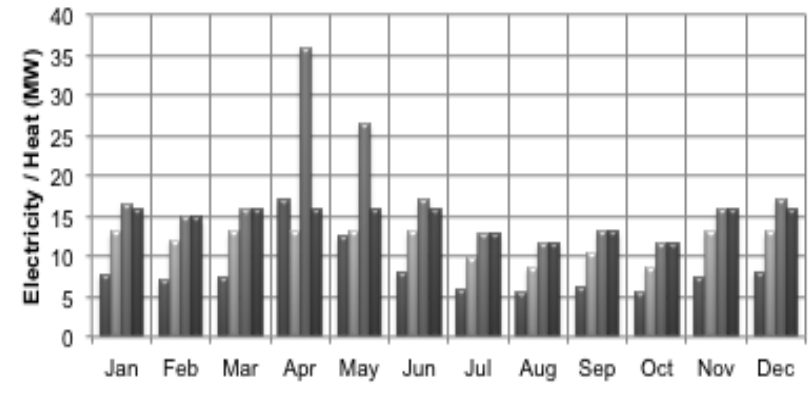

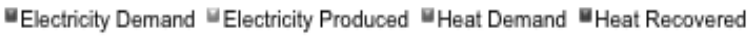

Fig. 8. Operating strategy for case three. 
The extreme unprofitability of case three can be attributed to the fact in addition to the carbon pricing liability; the system was operating at $100 \%$ capacity in seven months of the year. When the system operates at the higher capacity $(100 \%$ partial load), more electricity is produced as well as increased levels of recovered heat. As more heat is recovered through the operation of the gas turbine, the back-up boiler can be used minimally and hence reducing the overall amount of carbon emissions released from the system. This is the overall aim of being financially liable for the carbon price. The additional electricity was fed into the grid for payment of the feed-in tariff, however this feed-in tariff was not sufficient nor the quantities of excess electricity produced large enough to affect the overall profitability of the system.

\section{CONCLUSION}

This work showed in the context of the chosen case study, the steam turbine system analyzed in [1] is much more suited in terms of economic benefit than the gas turbine based system which resulted in an unprofitable system in each of the three economic cases and possessed no potential to recover the capital costs. This is due to the fact that the required heat in the case study is much greater than electricity demand. This characteristic of the chosen demand profile contributed to the unprofitable results.

However, some of the conclusions drawn and discussed in [1] are still valid in this study. Due to the increase in the price of electricity relative to the price of fuel, the system became more profitable after the introduction of the carbon price supporting the implementation of on-site power and heat generation. Additionally, the carbon price aims to impose a financial liability great enough to encourage research into alternate methods of electricity and consequently heat generation that are less carbon intensive. Since the overall profitability in case three was reduced, Australia's carbon pricing policy has succeeded in this respect in the context of this particular system. The methodology used to derive the results as well as the system described is dynamic and therefore it can be applied to many other case studies in order to provide a comprehensive study as to the impact of Australia's carbon pricing policy.
Ultimately, possible future work in regards to this system would entail revisiting the steam turbine system in [1] and operating the system on a renewable source such as biomass combusted directly in the boiler. Investigation into renewable sources is beneficial as currently power generations through these methods are exempt from financial liability under Australia's carbon pricing policy. Whilst the short term potential of such an investigation in an Australian context is limited due to renewable energy still being in its infancy in Australia, the long term potential is significant due to the increase in the presence of carbon pricing policies both domestically in Australia and internationally throughout the world.

\section{REFERENCES}

[1] C. A. Gibson, M. A. Meybodi, and M. Behnia, "Optimisation and selection of a steam turbne for a large scale CHP system under Australia's carbon price," Energy, vol. 61, pp. 291-307.

[2] Catalog of CHP Technologies, U.S. Environmental Protection Agency Combined Heat and Power Partnership, 2008.

[3] M. A. Meybodi and M. Behnia, "Optimum sizing of the prime mover in a medium scale gas turbine CHP system," Journal for Engineering Gas Turbines and Power, vol. 113, issue 11, 2011.

[4] Commonwealth of Australia. (2011). Clean energy act 2011 No. 131 2011.[Online].

Available: http://www.comlaw.gov.au/Details/C2011A00131

[5] Australian Government. (2012). Linking and Australian liable entities. [Online]. Available: http://www.cleanenergyfuture.gov.au/linking-and-australian-liable-en tities/

[6] Australian Government. (2011). How do companies estimate carbon emissions? [Online]. Available: http://www.cleanenergyfuture.gov.au/wp-content/uploads/2011/11/fa ct-sheet-20-estimating-emissions-2-PDF.pdf

[7] Australian Government Department of Climate Change \& Energy Efficiency. (2011). National greenhouse accounts factors. [Online]. Available:http://www.climatechange.gov.au/publications/greenhouseacctg/national-greenhouse-factors.aspx

[8] Z. Lian, K. Chua, and S. Chou, "A thermoeconomic analysis of biomass energy for tr igeneration," Applied Energy, vol. 87, pp. 84-95, 2010 .

Chanel A. Gibson received her bachelor of engineering in mechanical engineering from The University of Sydney, Australia in 2011.

She is currently pursuing her $\mathrm{PhD}$ at the University of Sydney, Australia in mechanical engineering. Her research interests include the areas of combined heat and power systems, thermo-economic optimization and the impact carbon pricing has on these systems. 